\title{
Long-term Remission of Metastatic Pleomorphic Paratesticular Rhabdomyosarcoma with Chemotherapy in an Adolescent Boy - A Case Report
}

\begin{abstract}
Rhabdomyosarcoma (RMS) is the most common soft tissue sarcoma in the pediatric age group They are classified based on the histopathological characteristics. The prognosis of RMS depends on the site of occurrence and the histopathology. Although paratesticular site is considered as one of the favorable sites, pleomorphic histology, even at this favorable site, confers a poor prognosis. Treatment includes surgery chemotherapy and radiation in metastatic cases. Here, we describe a case of an adolescent boy with pleomorphic paratesticular RMS treated successfully with chemotherapy.
\end{abstract}

Keywords: Chemotherapy, pleomorphic, prognosis, rhabdomyosarcoma

\section{Introduction}

Sarcomas are malignancies that arise from bone and soft tissues. In children, rhabdomyosarcoma (RMS) is the most common soft tissue sarcoma. It commonly affects children more than adults. The pleomorphic type of RMS typically affects older age group and adults. Prognosis depends on the histological type and the location of the tumor. Here, we describe a child with paratesticular pleomorphic RMS. Although paratesticular region is a favorable site, pleomorphic paratesticular RMS has a very bad prognosis.

\section{Case Report}

A 16-year-old Indian boy presented with complaints of painless left testicular swelling for 3 months. On examination, there was a nontender left testicular swelling. Systemic examination was within normal limits. Ultrasound of the abdomen showed left paratesticular swelling suggestive of left epididymal adenomatoid tumor. He was evaluated with alpha-fetoprotein (AFP), human chorionic gonadotropin (HCG), and lactate dehydrogenase (LDH), which were within normal limits (AFP - $1.54 \mathrm{ng} / \mathrm{ml}$, HCG - $0.1 \mathrm{IU} / \mathrm{L}$, and LDH - $323 \mathrm{U} / \mathrm{L})$. He underwent left high inguinal orchidectomy. Histopathological examination of the resected specimen showed spindle-shaped

\footnotetext{
This is an open access journal, and articles are distributed under the terms of the Creative Commons Attribution-NonCommercialShareAlike 4.0 License, which allows others to remix, tweak, and build upon the work non-commercially, as long as appropriate credit is given and the new creations are licensed under the identical terms.
}

For reprints contact: WKHLRPMedknow_reprints@wolterskluwer.com cells exhibiting moderate pleomorphism [Figure 1]. Immunohistochemistry was positive for vimentin and myf-4, focally positive for desmin, smooth muscle actin, and muscle-specific actin, and negative for $\mathrm{S} 100$, AFP, CD117, placental alkaline phosphatase, beta-HCG, and CD30, which was consistent with paratesticular pleomorphic RMS. Fluorodeoxyglucose positron emission tomography (PET) computed tomography scan done showed a mass lesion in the lower left transverse abdominis muscle, metabolically active left para-aortic lymph nodal mass, osteosclerotic lesion in the L3, T10, and T11 vertebral bodies and in the posterior end of the left rib, suggestive of metastatic deposits [Figure 2]. Treatment options - palliative versus curative - were explained in detail to the family. Curative treatment was attempted after discussions with the multidisciplinary team and the family. Chemotherapy was given as per the European Pediatric Soft tissue Sarcoma Study Group 2005. He received nine cycles of chemotherapyfour cycles of ifosfamide, vincristine, and actinomycin (IVA) doxorubicin (ifosfamide $3 \mathrm{~g} / \mathrm{m}^{2}$, vincristine $1.5 \mathrm{mg} / \mathrm{m}^{2}$, dactinomycin $1.5 \mathrm{mg} / \mathrm{m}^{2}$, and doxorubicin $30 \mathrm{mg} / \mathrm{m}^{2}$ ) followed by five cycles of IVA. The interval between cycles was 3 weeks. Radiation was proposed as consolidation therapy, but the family refused treatment due to nonmedical reasons.

\footnotetext{
How to cite this article: Mehdi I, Ranjani S, Swamy S, Venkatachala K. Long-term remission of metastatic pleomorphic paratesticular rhabdomyosarcoma with chemotherapy in an adolescent boy - A case report. Indian J Med Paediatr Oncol 2020;41:745-7.
}

\section{Intezar Mehdi', Shashi Ranjani ${ }^{1}$, Shivakumar Swamy², K Venkatachala ${ }^{3}$}

${ }^{I}$ Department of Pediatric Hematology and Oncology and Bone Marrow Transplantation, Health Care Global, Bengaluru, Karnataka, India, ${ }^{2}$ Department of Radiodiagnosis, Health Care Global, Bengaluru, Karnataka, India, ${ }^{3}$ Department of Surgical Oncology, Health Care Global, Bengaluru, Karnataka, India

Submitted: $27-$ Feb-2020 Revised: 26-May-2020 Accepted: 27-May-2020 Published: 29-Oct-2020

Address for correspondence: Dr. Intezar Mehdi, HCG Towers No. 8, Kalinga Rao Road, Sampangiram Nagar, Bengaluru - 560095 , Karnataka, India.

E-mail:drintezar@gmail.com

Access this article online Website: www.ijmpo.org

DOI: 10.4103/ijmpo.ijmpo_85_20 Quick Response Code:

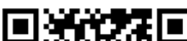
atrat

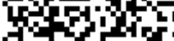
Fiping alchtsa 


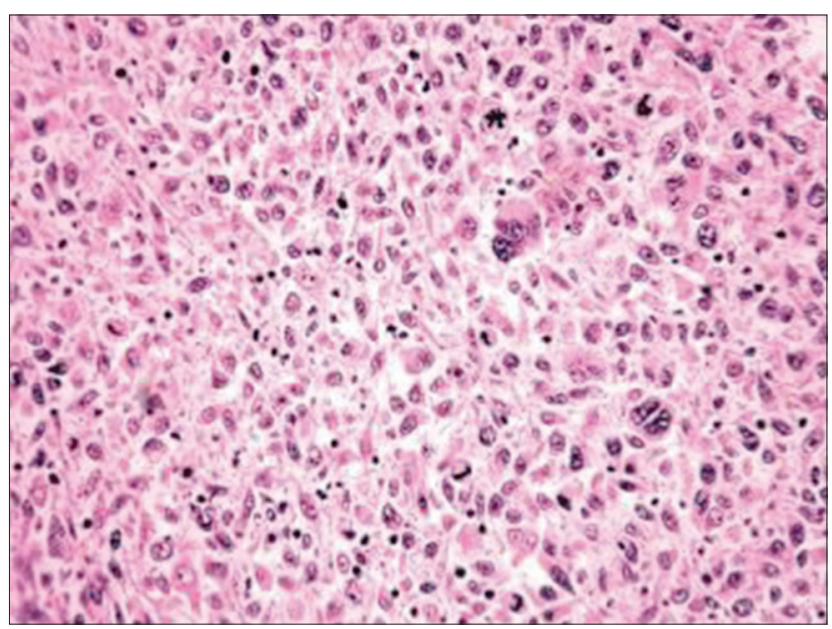

Figure 1: Histopathological examination showing spindle-shaped cells with moderate pleomorphism

The child was followed up regularly. Follow-up PET scans in 2017 showed complete resolution of the lesions. At present, he is 5 years' posttreatment and is doing well.

\section{Review of Literature}

Sarcomas are rare tumors that arise from the bone and the soft tissues. They constitute $20 \%$ of all mesenchymal malignancies. Eighty percent of sarcomas arise from soft tissues and $20 \%$ from the bones. ${ }^{[1]}$ RMS is the most common soft tissue sarcomas in the pediatric age group and accounts for $40 \%$ of all soft tissue sarcomas in children. ${ }^{[2]}$ It is a highly malignant mesenchymal tumor originating from the immature striated muscles and is composed of undifferentiated round and spindle cells that display skeletal-muscle differentiation without embryonal or alveolar components. ${ }^{[3,4]}$ Spalteholz et al. reported that $80 \%$ of RMS occurs in children below 12 years, whereas Boudahna et al. observed that RMS has two peaks one at the age of 4 years and the second at 18 years. ${ }^{[1,5]}$ Lee et al. also reported that $80 \%$ of cases occur before 21 years of age and the rest $20 \%$ occur in adults. ${ }^{[6]}$ RMS is more common in boys with a ratio of $3: 1 .^{[3]}$

RMS usually involves the head and neck region, extremities, and genitourinary areas. Only $20 \%$ of RMS arises from the genitourinary system. ${ }^{[3,5]}$ Based on the histological features, RMS is classified as embryonal (67\%), alveolar (32\%), and pleomorphic (1\%). ${ }^{[7]}$ Embryonal and alveolar variants are more common in children, whereas pleomorphic RMS affects adults and adolescent children. ${ }^{[8]}$ Any type of RMS may occur in the paratesticular region.

Paratesticular RMS is a rare tumor arising from the mesenchymal tissues of the spermatic cord, epididymis, testis, and testicular tunics. ${ }^{[5]}$ Embryonal RMS arising in the paratesticular region in young males is a common entity; however, pleomorphic RMS in such location is quite rare. ${ }^{[9]}$ The most common presentation of paratesticular RMS, similar to our child, is a painless swelling. ${ }^{[3]}$

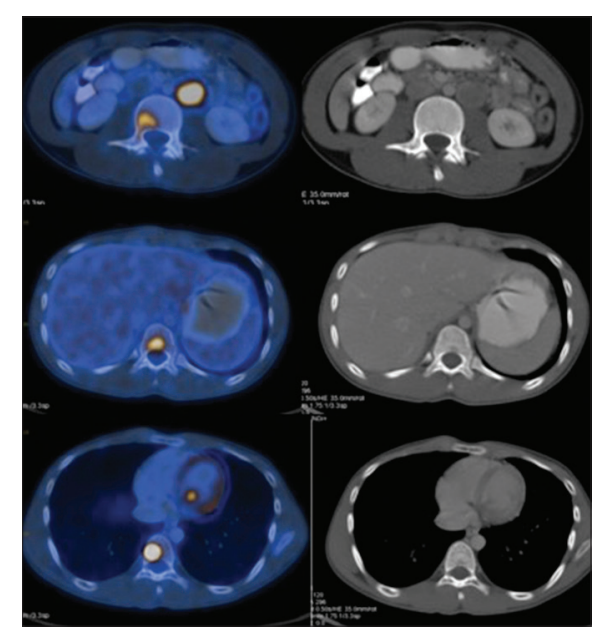

Figure 2: Skeletal metastases on fluorodeoxyglucose positron emission tomography computed tomography

Paratesticular RMS is usually diagnosed earlier, owing to its superficial location. ${ }^{[6]}$ Histopathologically, pleomorphic RMS contains spindle-shaped cells with blunted central nuclei, similar to our child. Jonathan et al. compared the histological features of different types of RMS and reported that in contrast to a monotonous population of round and ovoid cells that are found in alveolar RMS and ovoid to spindle cells that are usually described in embryonal RMS, pleomorphic RMS showed markedly atypical spindle and polygonal cells, often with bizarre forms. They reported that this could be the reason for their aggressive behavior and poor response. ${ }^{[4]}$ The tumors usually express muscle-specific markers such as MyoD and vimentin. These markers are usually present during fetal muscle development. ${ }^{[10]}$ Spalteholz et al. reported that myoglobin and fast skeletal muscle myosin are the most sensitive markers for pleomorphic RMS. ${ }^{[1]}$

RMS has a high propensity to metastasize. Metastasis is mostly by lymphatics to the iliac and para-aortic nodes, but hematogenous spread also occurs to the lungs and liver. ${ }^{[5]}$ Pleomorphic (47\%) and alveolar (39\%) RMS commonly presented with distant disease, in contrast to embryonal RMS (25\%). ${ }^{[7]}$

The prognosis of RMS depends on the site of the tumor and its histology. The favorable sites are orbit, head and neck (excluding parameningeal), and genitourinary (nonprostate, nonbladder). A primary paratesticular site is considered to have a favorable prognosis. ${ }^{[6]}$ Based on the histology, embryonal and alveolar types have better prognosis. Pleomorphic and mixed type have poor prognosis. ${ }^{[3,6]}$ Price et al. observed that pleomorphic RMS occurred more in adults and had a median survival of 2.25 years. $^{[11]}$ Furthermore, age was also noticed to be a prognostic factor, with adults having a worse prognosis than children. ${ }^{[5]}$

Paratesticular tumors are primarily treated with high orchidectomy. Adjuvant chemotherapy with radiation 
is advised for metastatic RMS. ${ }^{[3]}$ In cases of regional lymph node metastasis, the role of retroperitoneal lymph node dissection is controversial, and most authors prefer radiotherapy for the treatment of lymph node metastasis. ${ }^{[3]}$

\section{Conclusion}

Pleomorphic paratesticular RMS is a rare and aggressive tumor. Although paratesticular region is considered as a favorable site in RMS, pleomorphic paratesticular RMS has a poor prognosis. This rare tumor should be suspected in adolescent and older boys with testicular swelling. Although it has a poor prognosis, treatment with surgery, chemotherapy, and radiation has improved survival.

\section{Declaration of patient consent}

The authors certify that they have obtained all appropriate patient consent forms. In the form the patient(s) has/have given his/her/their consent for his/her/their images and other clinical information to be reported in the journal. The patients understand that their names and initials will not be published and due efforts will be made to conceal their identity, but anonymity cannot be guaranteed.

\section{Financial support and sponsorship}

Nil.

\section{Conflicts of interest}

There are no conflicts of interest.

\section{References}

1. Spalteholz M, Gulow J. Pleomorphic rhabdomyosarcoma infiltrating thoracic spine in a 59-year-old female patient: Case report. GMS Interdiscip Plast Reconstr Surg DGPW
2017;6:Doc11.

2. Ognjanovic S, Linabery AM, Charbonneau B, Ross JA. Trends in childhood rhabdomyosarcoma incidence and survival in the United States, 1975-2005. Cancer 2009;115:4218-26.

3. Boulma R, Gargouri MM, Sallemi A, Chlif M, Fitouri Z, Kallel Y, et al. Para testicular pleomorphic rhabdomyosarcoma: A report of two cases. Case Rep Urol 2013;2013:807979.

4. Noujaim J, Thway K, Jones RL, Miah A, Khabra K, Langer $\mathrm{R}$, et al. Adult pleomorphic rhabdomyosarcoma: A multicenter retrospective study. Anticancer Res 2015;35:6213-7.

5. Boudahna L, Benbrahim Z, Amaadour L, Mazouz A, Benhayoune K, Tahiri Y, et al. Para testicular rhabdomyosarcoma in adults: Three case reports and review of literature. Pan Afr Med J 2014;19:279.

6. Lee HY, Tsai CC, Huang CH, Li WM, Yeh HC, Wu WJ, et al:SLepi Mixed-type para testicular rhabdomyosarcoma: A case report.si Kaohsiung J Med Sci 2011;27:239-241.

7. Perez EA, Kassira N, Cheung MC, Koniaris LG, Neville HL, Sola JE, et al. Rhabdomyosarcoma in children: A SEER population based study. J Surg Res 2011;170:e243-51.

8. Ozaslan E, Berk V, Baldane S, Eker B, Bozkurt O, Senol $\mathrm{S}$, et al. Primary pleomorphic rhabdomyosarcoma of thyroid gland in an adult patient: A case report. Eurasian J Med 2016;48:69-72.

9. Kishore B, Khare P, Gupta RJ, Gupta C, Khare V. A rare case of paratesticular pleomorphic rhabdomyosarcoma diagnosed by fine needle aspiration: A case report. Diagn Cytopathol 2010;38:121-6.

10. Goldstein M, Meller I, Issakov J, Orr-Urtreger A. Novel genes implicated in embryonal, alveolar, and pleomorphic rhabdomyosarcoma: A cytogenetic and molecular analysis of primary tumors. Neoplasia 2006;8:332-43.

11. Price RL, Bingmer $\mathrm{K}$, Harkins L, Iwenofu $\mathrm{OH}$, Kwon $\mathrm{CH}$, Cook $\mathrm{C}$, et al. Cytomegalovirus infection leads to pleomorphic rhabdomyosarcomas in Trp53+/- mice. Cancer Res 2012;72:5669-74. 